Report

\title{
Rodents: another group of animal hosts of visceral leishmaniasis in Meshkin-Shahr district, Islamic Republic of Iran
}

\author{
M. Mohebali,' B. Poormohammadi,' A. Kanani, ' H. Hajjaran 'and G.H. Edrissian'
}

\section{Introduction}

Visceral leishmaniasis (VL), or kala-azar, is an endemic disease in some areas of Ardabil Province in the north-west and Fars Province in the south of the Islamic Republic of Iran. In other provinces of the country, the disease has been reported in sporadic form $[I-4]$. Although dogs are the main source of infection for human VL, at least in the endemic foci of the country [I], wild carnivores such as jackals and foxes have also been found infected with Leishmania spp. and are considered as animal reservoirs of infection, particularly in areas where sporadic cases of disease have been reported $[4,5]$.

In this investigation, a serological and parasitological survey of $V L$ in rodents was carried out during 1994-96 in the endemic focus of Meshkin-Shahr district of Ardabil Province. This study shows that some of the rodents in highly endemic zoonotic visceral leishmaniasis (ZVL) areas may also have a role in transmission of the disease to children and animals.

\section{Materials and methods}

Rodents were trapped alive in various parts of the Meshkin-Shahr area. Before killing the caught rodents, blood samples were collected from each of them in two heparinized capillary tubes. These samples were tested in the kala-azar laboratory of Imam Khomeini Hospital in the MeshkinShahr district by direct agglutination test (DAT), according to the methods described by Harith et al. [6,7].

The spleen and liver samples of seropositive rodents ( $\geq 1: 100$ in DAT) were cultured in Novy-MacNeal-Nicolle (NMN) + liver infusion tryptose (LIT) mediuns and checked twice a week for six weeks. A total number of 2514 smears were prepared from the blood (thick and thin) and interinal organs, including spleen and liver (impression smears). The smears were prepared from all animals and were stained with standard Giemsa stain and examined microscopically for the amastigote form of Leishmania. The promastigotes isolated in the culture media were characterized by isoenzyme technique.

\section{Results}

Altogether, 419 rodents of five species were trapped alive in various parts of the Meshkin-Shahr area. Fifteen (15) (3.6\%) were Cricetulus migratorius (grey hamster)

'School of Public Hoalth and Inctitute of Public Hoalth Rocoarch, Tohoran, Iclamio Ropublic of Iran. Received: 01/05/97; accepted: $15 / 01 / 98$ 
and seven $(1.7 \%)$ were $M u s$ musculus; both species were caught inside homes. Three hundred and ninetyfour (394) Meriones persicus (94.0\%), two Mesocricetus auratus $(0.5 \%)$ and one Alactaga sp. $(0.2 \%)$ were trapped outside villages. The results of the parasitological and serological tests are shown in Table 1.

Leishmania spp. were isolated from spleens of two Mer. persicus and one Mes. auratus in NMN + LIT culture media. The promastigotes isolated from Mer persicus were characterized as $L$. donovani zymodeme LON-50 and promastigotes Isolated from Mes. aurarus were determined as $L$. infantum zymodeme LON-49 by isoenzyme technique.

\section{Discussion}

In one study, Mer persicus was reported to be naturally infected with Leishmania in East A zerbaijan, in the north of the Islamic Republic of Iran $[8]$. In the smears prepared from the cutaneous lesion of Mer persicus, considerable numbers of amastigotes were seen. Microscopic examination of the smears prepared from the internal organs and blood of this rodent did not show any amastigotes.

In this study, amastigotes were observed in $16.5 \%$ of the rodents after microscopical examination of the smears prepared from internal organs. $L$. donovani LON-50 was isolated from two Mer. persicus. Previously, this strain of Leishmania had been isolated from rodents in eastern Turkey, and from humans in Ethiopia, Kenya and Sudan (D. Evans, personal communication,

$$
\begin{aligned}
& \text { ज. } \\
& -1 \\
& \text { 过 } \\
& \nabla 1
\end{aligned}
$$

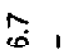$$
-1
$$$$
\text { 怘 }
$$$$
\infty 1
$$

웅

8

$\infty 6$

$\stackrel{\circ}{8} \stackrel{8}{ \pm}$

m -

$$
\text { r }
$$$$
11
$$$$
\text { I \& } 1
$$$$
\begin{aligned}
& 7 \\
& 0
\end{aligned}
$$$$
\text { | } \mathbf{1}
$$$$
\infty
$$$$
\text { 员 }
$$$$
\text { T }
$$$$
- \pm 1
$$$$
8 \frac{0}{8} 1
$$$$
\infty
$$$$
8 \div 18
$$$$
\text { 一志 I 荡 }
$$$$
\text { के }
$$$$
\text { 帝 品 }
$$$$
\text { 영 } 1 \text { 뭉 }
$$$$
-\infty 1 m
$$$$
\text { I I }
$$$$
\stackrel{m}{\infty} 1
$$$$
8 \stackrel{\infty}{6}, \quad \frac{1}{6}
$$$$
\text { N I }
$$$$
-8
$$$$
8
$$$$
\stackrel{N}{n}
$$$$
\text { N }
$$
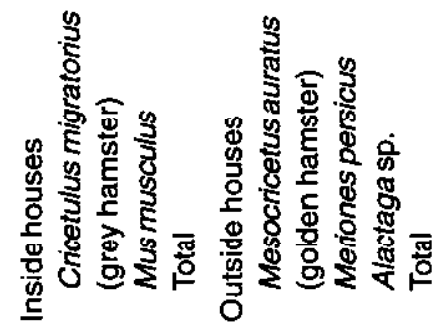
1996). Therefore, it is possible that it is transmitted from rodents to humans in this endemic area.

L. infantum LON-49 was isolated from one of Mes. auratus. This species of Leishmania is zoonotic and had been previuusly isolated from humans [2] and dogs in the Meshkin-Shahr area, and from dogs in the Kordan area in Karaj districl, west Teheran. In addition to humans and dogs, wild carnivores such as jackals and foxes have been found infected with Leishmanta in the Islamic Republic of Iran [3,5]. Of course, L. infantum has been isolated previously, from Rattus rattus in Italy and Iraq [9]. As this study found natural Leishmania infection of rodents in ZVL highly endemic areas, rodents may also have a role in transmission of the disease to children, par- ticularly those rodents living inside homes. Further studies may clarify the exact role rodents play as animal reservoirs of kalaazar in the studied areas.

\section{Acknowledgements}

We wish to express our thanks to Dr A. Nadim for advice and critical comments; to Dr D. Evans and Mr S. Mazlumi, Department of Medical Parasilology, London School of Hygiene and Tropical Medicine, for their collaboration in isoenzyme characterization of the isolated Leishmania strains; to S. Anvari for performing DAT in the Meshkin-Shahr kala-azar laboratory; and to Dr S. Shojaei for hls assistance in catching the rodents.

\section{References}

1. Edrissian $\mathrm{GH}$ et al. An endemic tocus of viseral leishmaniasis in Meshkin-Shahr, east Azerbaijan province, north-west part of Iran. Bulletin de la societé de pathologie exotique et de ses filiales, 1988, 81(2):238-48.

2. Edrissian GH. Kala-azar in Iran. Medical journal of the Islamic Republic of Iran, 1990, 4(3):235-7.

3. Edrissian $\mathrm{GH}$ et al. Serological studies of visceral leishmaniasis and search for animal resorvoirs in Fars Province, southern Iran. Iranian journal of medical sciences, 1993, 18(3):99-105.

4. Nadim A et al. Present status of kala-azar in Iran. American journal of tropical medicine and hygiene, 1978, 27(1):25-8.

5. Hamidi AN ot al. Visooral loishmaniaois of jackals and dogs in northern Iran. Transactions of the Royal Society of
Tropical Medicine and Hygiene, 1982, 76(6):756-7.

6. Harith A et al. Improvement of direst agglutination test for field studies of visceral leishmaniasis. Journal of clinical microbiology, 1988, 26(7):1321-5.

7. Harith A et al. Application of direct agglutination test for detection of specific antiLeishmania antibodies in the canine reservoir. Journal of clinical microbiology, 1989, 27(10):2252-6.

8. Edrissian $\mathrm{GH}$ ot al. Meriones persicus, another probable reservoir of zoonotic cutaneous leishmaniasis in Iran. Transactions of the Royal Society of Tropical Medicine and Hygiene, 1975, 69(56):517-9.

o. Desjeux, P. Information on the epidemiology and control of the leishmaniases by country or territory. Geneva, World Health Organization, 1991 (unpublished document WHO/LEISH/91.30). 